\title{
ТРУДОВАЯ ДЕЯТЕЛЬНОСТЬ ОСУЖДЕННЫХ ЗА ПРЕДЕЛАМИ ИСПРАВИТЕЛЬНЫХ УЧРЕЖДЕНИЙ: ДОПУСТИМОСТЬ И ПРОБЛЕМЫ РЕАЛИЗАЦИИ
}

\section{THE LABOUR ACTIVITIES OF CONVICTS OUTSIDE THE CORRECTIONAL INSTITUTIONS: THE VALIDITY AND PROBLEMS OF IMPLEMENTATION}

\section{Shershnev}

Summary. Objective: to Develop theoretical provisions on the effectiveness, permissibility and expediency of measures of re-socialization of convicts in the form of their work outside of correctional institutions.

Methods: methods of analysis, synthesis, deductive, formal-legal, statistical methods were used in the preparation of the material.

Results: proposed the concept that the current replacement of the unserved part of punishment by softer kind of punishment is applied in a modified form not only as incentives for positive actions of the convicted person for the period of punishment, but as a measure of re-socialization, the application of which should be aimed at the majority of prisoners.

Conclusions: The article concludes with the conclusion about the applicability of these practices and their role in the resocialization of prisoners.

Keywords: penitentiary system; resocialization; convicts; reoffending; labor activity of prisoners.

\section{Ввемение}

$\mathbf{H}$ а текущий момент проблема рецидива преступлений в России стоит не менее остро. Несмотря на снижение уровня рецидива преступлений в целом [8, с. 43], удельный вес рецидивистов среди лиц, совершивших преступления, по-прежнему крайне высок. Рецидивная преступность представляет собой повышенную общественную опасность, нежели совершенная впервые $[10$, с. 33], чем и обусловлена острота данной проблемы.

На сегодняшний день проблема рецидива преступлений широко обсуждается в научном сообществе. Наибольшее распространение имеют вопросы возник-

\author{
Шеринев Михаил Николаевич \\ Аспирант, Сургутский государственный \\ университет \\ kpbb86@gmail.com
}

Аннотация. Цель. Разработка теоретических положений об эффективности, допустимости и целесообразности меры ресоциализации осужденных в виде их трудовой деятельности за пределами исправительных учреждений.

Методы. При подготовке материала использовались методы анализа, синтеза, дедуктивный, формально-юридический, статистический методы.

Результаты. Была предложена концепция, согласно которой существующая на сегодняшний день замена неотбытой части наказания более мягким видом наказания применяется в видоизмененном виде не только в качестве меры поощрения за положительные действия осужденного за период отбывания наказания, но как мера ресоциализации, применение которой должно быть направлено на большинство осужденных.

Выводы. В завершении статьи делается вывод о применимости данных практик и их роли в ресоциализации осужденных.

Ключевые слова: пенитенциарная система; ресоциализация; осужденные; рецидив преступлений; трудовая деятельность заключенных.

новения и предупреждения рецидивной преступности. Несмотря на различные формулировки причин рецидива преступлений, приводимые факторы, преимущественно, совпадают у многих авторов, отличаясь лишь степенью конкретизации.

Однако, отметим тот факт, что существуют различные подходы к понятию рецидива преступлений. Так, выделяют уголовно-правовой, криминологический и пенитенциарный рецидив преступлений [5, с. 63]. С учетом изложенного выразим мнение, что во многом отличия подходов к понятию рецидива преступлений и обусловливают различие в приводимых причинах его возникновения и увеличения. 
Ф.Р. Хисамутдинов и А.Е. Шалагин приводят следующие причины и условия рецидивной преступности:

1. Социально-экономические факторы;

2. Нравственно-психологические факторы;

3. Нормотворческие и правоприменительные факторы;

4. Семейно-бытовые факторы;

5. Личностно-субъективные факторы;

6. Иные факторы [10, с. 33].

Предупреждение рецидива преступлений представляется нам ключевой задачей, стоящей перед обществом и государством, ввиду обозначенной ранее повышенной социальной опасности повторных преступлений, а также весьма значительной доли преступников-рецидивистов в общей массе лиц, совершивших преступления.

\section{Материалы \\ и мето $\Delta \mathrm{b}$}

При подготовке материала мы опирались на теоретические предположения касательно возможности осуществления меры ресоциализации в виде обеспечения краткосрочных периодических контактов осужденных с обществом на свободе для предотвращения полной утраты социальных связей на период отбывания наказания, а также противодействия смене поведенческих паттернов за указанный период. В изоляции от общества осужденный адаптируется к условиям, в которых он пребывает продолжительный период, и десоциализируется еще больше.

Полная изоляция от «внешнего мира» влечет за собой ослабление исправительной функции пенитенциарной системы. Осужденные после отбывания наказания должны вернуться в общество и реинтегрироваться в него. Как следствие, контакты с внешним миром необходимо сохранить, соблюдая баланс между карательной и исправительной функциями исправительных учреждений.

Предлагая концепцию краткосрочных трудовых «каникул» для осужденных, мы предлагаем расширить контакты с обществом - не только с семьей, но и с посторонними людьми, что при освобождении посодействует более быстрой и безболезненной реинтеграции в общество.

\section{^итературный обзор}

Влияние трудовой занятости осужденных в качестве меры профилактики рецидивной преступности находит свое отражение в работах Н. А. Беляева [4], Д.Д. Данилова [6], И.Г., Константинова [7] и др.
В данных работах освещаются вопросы роли труда в формировании личности заключенных, необходимости привлечения осужденных к производственному труду, являющемуся одним из основных средств воспитательного воздействия.

Весьма обширный список причин рецидивной преступности и мер ее предупреждения содержится в работах Н.С. Артемьева и А.Н. Бурчихина, И.В. Батыщевой и В.Г. Козырева, а также Ф.Р. Хисамутдинова и А.Е. Шалагина.

Вопросы психологического состояния осужденных на момент освобождения от отбывания наказания раскрываются в статье А.Р. Абуталипова [1]. На основании его идей мы смогли определить вектор движения в определении наиболее предпочтительных мер ресоциализации осужденных к лишению свободы в контексте поставленной цели.

\section{Результаты и обсужления}

Говоря о мерах предупреждения рецидива преступлений, ученые называют такие меры, как совершенствование законодательства в соответствующих отраслях, повышение квалификации специалистов оперативных подразделений, создание специализированной службы постпенитенциарного контроля [2, с. 112]. Также предлагается выявление и устранение причин и условий, способствующих совершению преступлений ранее судимыми лицами, оказание содействия в трудовом и бытовом устройстве лицам, отбывшим наказание [9, с. 286] и т.д.

Особенно выделим содействие в трудовом и бытовом устройстве указанных лиц. По мнению М.В. Степанова, на этом необходимо сделать акцент, как на формы поддержки, имеющие приоритетное значение для любых граждан [9, с. 286]. Полностью согласимся с автором. В соответствии с исследованием А.Р. Абуталипова, осужденные при освобождении испытывают гамму чувств, при этом преобладают «Душевный подъем и надежда изменить свою жизнь к лучшему», «Потерянность и растерянность», «Ощущение своей ненужности», «Страх перед будущим» $[1$, с. 157].

Повторимся - среди негативных ощущений, испытываемых освобожденными от отбывания наказания в виде лишения свободы значительную часть (45,2\%) занимают три последних из указанных выше. На наш взгляд, содействие в преодолении указанных негативных чувств может оказать гарантия бытового и трудового устройства.

Однако, на наш взгляд, для более полной реализации подобной меры необходима заблаговременная подго- 
товка осужденного к освобождению от отбывания наказания.

Продолжительное пребывание в условиях, установившихся в исправительных учреждениях, особенно - в обществе лиц, демонстрирующих девиантную направленность личности, крайне негативно сказываются на последующей ресоциализации. Осужденные адаптируются к новым условиям, весьма отличным от таковых на свободе. Впоследствии, их повторная адаптация к старому образу жизни осложнена, что ведет к совершению повторных преступлений. Возникает замкнутый круг, при котором преступник неоднократно совершает противоправные деяния, за что подвергается уголовному наказанию, уже не в состоянии своевременно приспособиться к жизни в обществе.

Для вывода осужденного из подобного цикла нам видится целесообразным такой механизм, как трудовая ресоциализация, идея которой имеет весьма широкое распространение.

На наш взгляд, подготовка осужденного к освобождению должна осуществляться не просто заблаговременно, но задолго до фактического освобождения с учетом вероятности условно-досрочного освобождения в соответствии с положениями ст. 79 УК РФ. Для этого мы находим целесообразным более плавное смягчение условий отбывания наказания, чем предусмотренное сегодня.

Под более плавным смягчением наказания мы подразумеваем трудовую деятельность за пределами исправительных учреждений на краткосрочный период. При этом не должно быть полной изоляции от работников данного учреждения. За осужденными, безусловно, необходим контроль, при этом суть подобной ресоциализация заключается именно в периодических контактах с обществом на свободе. В итоге планируется, что заключенный будет постепенно привыкать к социальной жизни на свободе под контролем сотрудников исправительных учреждений, и после освобождения процесс адаптации к новым условиям будет значительно упрощен. При этом, необходимо учитывать личность осужденного. Данная мера может быть применена только при условии отсутствия выраженной агрессии против других людей.

Как мы уже говорили выше, отсутствие внешних контактов препятствует ресоциализации осужденных. Навыки, образ мышления, опыт, полученные за период отбывания наказания, мешает их реинтеграции в общество. Поэтому, помимо непосредственно отбывания осужденными наказания в виде лишения свободы, пенитенциарная система должна сделать дополнительный акцент на вопросах ресоциализации, в том числе недо- пущения утраты социальных связей и социальных навыков осужденных.

Существующая на сегодняшний день система отбывания наказания не несет в себе исправительной функции в той мере, в какой это необходимо. Личность осужденного подавляется, он вынужден подстраиваться под существующие порядки, при этом данные порядки, повторимся, не направлены на исправление. Для предотвращения рецидива преступлений, необходим баланс между карательной и исправительной функциями, при этом данные функции зачастую вступают в противоречие между собой. Ресоциализация не может быть достигнута исключительно методом «кнута», но при этом человек, совершивший преступление должен понести наказание в полной мере. Подобное противоречие мы находим обязательным к разрешению.

И именно в контексте исправительной функции мы видим перспективным трудовую деятельность за пределами исправительных учреждений. На сегодняшний день замена лишения свободы трудовой деятельностью применяется в качестве поощрения осужденным за примерное поведение, в то время как подобная мера (с предложенными нами изменениями) должна использоваться как средство достижения положительной динамики в поведении осужденных. Внимание к личности осужденного и ее положительным качествам, к проблемам, детерминировавшим совершение им преступления, повлекшего уголовное наказание, а также ребалансировка функций уголовно-исполнительной системы, направленная на значительное усиление исправительной функции, переход к отношениям внутри данной системы по принципу «строгий, но справедливый», остро необходимы на сегодняшний день для достижения заявленных целей пенитенциарной системы. В совокупности с последующей гарантией трудоустройства, в том числе на предприятии, на котором осужденным осуществлялась трудовая деятельность, подобный комплекс мер должен поспособствовать положительной динамике уровня рецидива преступлений.

\section{Зак^ючение}

В рамках настоящей статьи мы предложили такую меру ресоциализации осужденных к лишению свободы, как трудовая деятельность за пределами исправительных учреждений, направленную на поддержание контактов осужденных с внешним миром. Данная мера - в теории - поспособствует повышению качества ресоциализации осужденных. При этом остро стоят организационный и финансовый вопросы, но при должной проработке данная мера может продемонстрировать необходимый результат. 


\section{ЛИТЕРАТУРА}

1. Абуталипов А. Р. Социальная структура и социальные институты в современном обществе // Гуманитарий юга России. — 2020. — Том 9 (41). — № 1. — C. 152-169.

2. Артемьев Н.С., Бурчихин А. Н. Причины и условия рецидивной преступности и основные меры её предупреждения // Вестник ВятГУ.— 2015.— № 5.— C. 110-114.

3. Батыщева И.В., Козырев В. Г. Причины и условия рецидивной преступности // Наука и современность. — 2015. — № 35. — С. 220 -223.

4. Беляев Н. А. Цели наказания и средства их достижения в исправительно-трудовых учреждениях [Текст] / Ленингр. ордена Ленина гос. ун-т им. А. А. Жданова.—Ленинград: Изд-во Ленингр. ун-та, 1963. - 186 с.

5. Волконская Е. К. Понятие криминологического рецидива преступлений // Вестник Московского университета МВД России. — 2015.— № 9.—C. 63-66.

6. Данилов Д. Д. Формирование социально-производственной системы в учреждениях, исполняющих наказание: Дис. ... канд. экон. наук: 08.00.05: МоСКва, 2004.- 213 C.

7. Константинов И.Г. Приобщение осужденных к труду. Введение в исправительно-трудовую экономику.- М.: Всесоюз. науч.-исслед. ин-т МВД СССР, 1982. - 160 c.

8. Состояние преступности в России за январь-декабрь 2019 г. // [официальный сайт Генеральной прокуратуры Российской Федерации] / Главное управление правовой статистики и информационных технологий. [Москва, 2020]. URL: https://genproc.gov.ru/upload/iblock/034/sbornik_12_2019.pdf (дата 0бpaщения: 14.05 .2020 г.)

9. Степанов М. В. Проблемы ресоциализации лиц, отбывших наказание в виде лишения свободы // Пробелы в российском законодательстве.- 2018. № 4.- - C. 285-288.

10. Хисамутдинов Ф.Р., Шалагин А. Е. Рецидивная преступность и ее предупреждение // Вестник Казанского юридического института МВД России. - 2015.№ 3 (21). - C. 32-37.

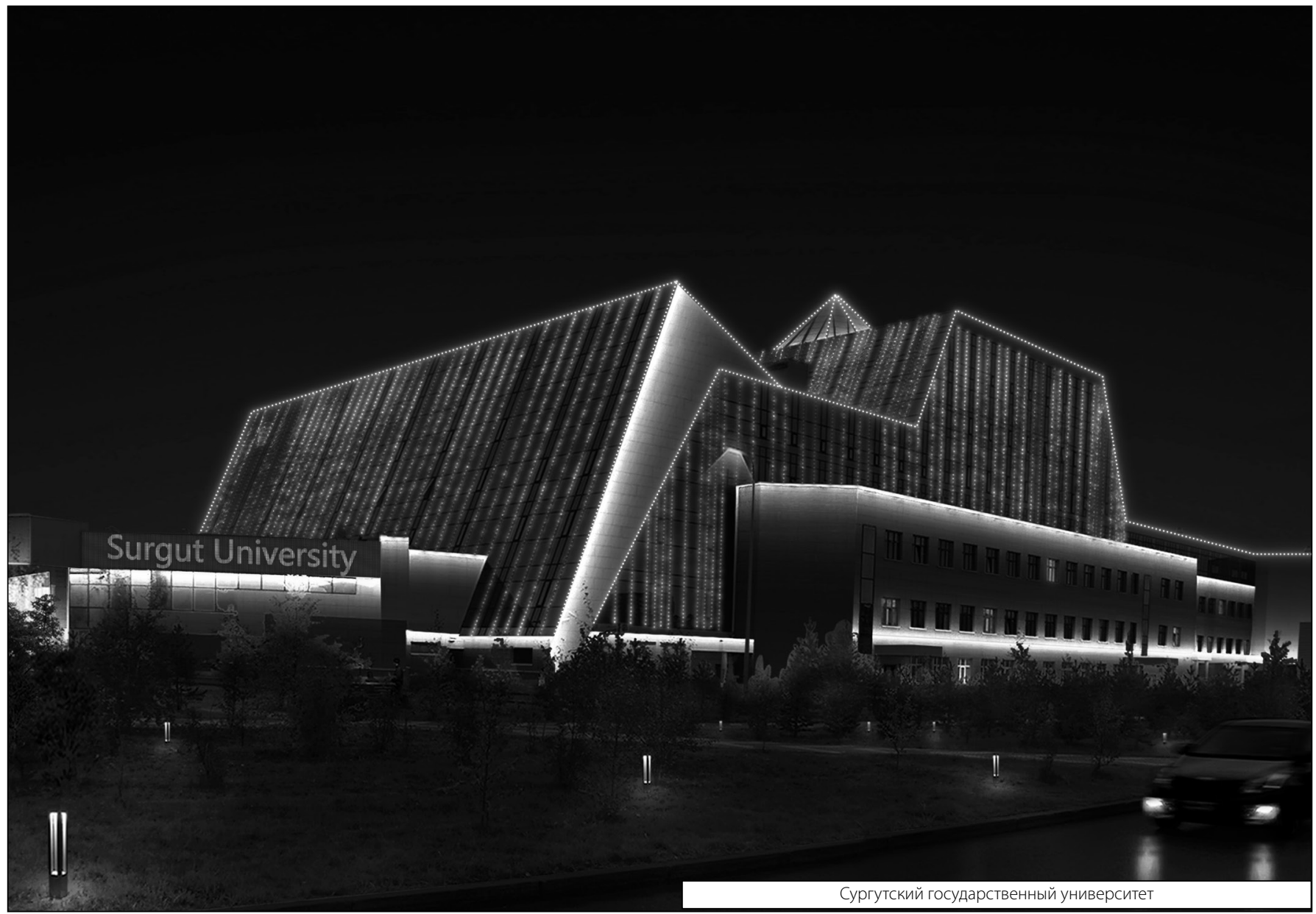

